\title{
Kinetics and DFT Studies of the Hydrogenation Reactions of Alkenes and Alkynes Catalyzed by (Benzoimidazol-2-ylmethyl)amine palladium(II) Complexes
}

\author{
Thandeka A. Tshabalala and Stephen O. Ojwach ${ }^{*}$ \\ School of Chemistry and Physics, Pietermaritzburg Campus, University of KwaZulu-Natal, \\ Private Bag X01, Scottsville 3209, South Africa
}

\begin{abstract}
A series of (benzoimidazol-2-ylmethyl)amine palladium(II) complexes have been employed as catalysts in the homogenous hydrogenation of alkenes and alkynes under mild conditions. A correlation between the catalytic activity and the nature of the ligand was established. Kinetic studies of the hydrogenation reactions of styrene established pseudo-firstorder dependence on styrene substrate. On the other hand, partial orders with respect to $\mathrm{H}_{2}$ and catalyst concentrations were obtained consistent with the formation of palladium(II) monohydride species as the active species. The nature of the solvent used influenced the hydrogenation reactions, where coordinating solvents resulted in lower catalytic activities. Density functional theory investigations provided valuable insights into the reactivity trends and influence of complex structure on the hydrogenation reactions.
\end{abstract}

Keywords: palladium; catalysts; hydrogenation; kinetics; DFT

*Corresponding author: Tel.: +27 (33) 260 5239; Fax: +27 (33) 2605009

E-mail: ojwach@ukzn.ac.za (S. O. Ojwach) 


\section{Introduction}

Hydrogenation reactions of alkenes and alkynes are currently one of the dominant industrial processes used for the reduction of unsaturated organic compounds to a wide range of relevant products. ${ }^{1-3}$ Several metal-based catalysts derived from nickel, palladium, ruthenium, rhodium, iridium and platinum have been employed in the catalytic hydrogenation of alkenes and alkynes under both homogenous ${ }^{4,5}$ and heterogeneous ${ }^{6,7}$ conditions. Currently, the major focus in transition metal catalyzed homogeneous molecular hydrogenation reactions has been on ligand design; and the insights gained so far show that the ability to control the catalytic behavior of these catalyst lies in the coordination environment around the metal atom.

To date, palladium(II) catalysts are currently receiving much attention in the hydrogenation of alkenes and alkynes due to their superior catalytic activities and selectivity. ${ }^{8}$ Numerous reports have appeared on the homogenous hydrogenation of alkenes and alkynes using palladium(II) catalysts supported on phosphine-donor ligands. For example, Bacchi et $a l^{9}$ and Drago et $a l^{10}$ employed hydazonic phosphine palladium(II) and bidentate (2,5-dimethylphospholano) palladium(II) complexes as effective catalysts in the hydrogenation of alkenes. Even though the phosphine-donor palladium catalysts have been successfully used in the homogeneous hydrogenation reactions of alkenes and alkynes, these systems suffer from lack of stability and sensitivity to moisture and air. ${ }^{11}$ As a results, nitrogen-donor palladium(II) catalysts are emerging as suitable alternatives due to their better stability and ease of synthesis in comparison to the phosphine-donor palladium(II) complexes. For example, the pyridine-2-carbaldine palladium(0) ${ }^{12}$ and bis(arylimino)acenaphthene palladium $(0)^{13}$ complexes have been shown to exhibit good selectivity and stability in the homogenous hydrogenation of alkynes. 
We recently reported the use of palladium(II) complexes anchored on (benzoimidazol-2ylmethyl)amine ligands ${ }^{14}$ to give active catalysts in the methoxycabonylation of higher olefins. Due to the promising results obtained in the methoxycabonylation reactions by these systems, we chose to explore their propensity to catalyze the molecular hydrogenation of selected alkenes and alkynes. In addition, kinetics and theoretical studies have been performed and are herein discussed.

\section{Experimental section}

\subsection{Materials and methods}

All moisture and air sensitive reactions were performed using standard Schlenk line techniques. Methanol (ACS reagent, $\geq 99.8 \%$ ), toluene (ACS reagent, $\geq 99.5 \%$ ), dichloromethane (ACS reagent, $\geq 99.8 \%$ ), absolute ethanol (ACS reagent, $\geq 98 \%$ ) and tetrahydrofuran (anhydrous, $\geq 99.9 \%)$ were purchased from Merck. Solvents were dried and distilled under nitrogen in the presence of suitable drying agents: Toluene and acetone were dried over anhydrous calcium chloride, methanol and absolute ethanol over calcium oxide, dichloromethane over phosphorus pentoxide and stored over $4 \AA$ molecular sieves. The ligands $N$-(1H-benzoimidazol-2-ylmethyl-2methoxy)aniline $\quad(\mathbf{L 1}), \quad N$-(1H-benzoimidazol-2-ylmethyl-2-bromo)aniline $\quad(\mathbf{L} 2), \quad N-(1 \mathrm{H}-$ benzoimidazol-2-ylmethyl)benzenamine $\quad(\mathbf{L 3}) \quad$ and $\quad N$-(1H-benzoimidazol-2ylmethylamino)benzenethiol (L4), were synthesized following the published literature method. ${ }^{15}$ The palladium complexes $\left[\mathrm{Pd}(\mathbf{L} \mathbf{1}) \mathrm{Cl}_{2}\right](\mathbf{1}),\left[\mathrm{Pd}(\mathbf{L} \mathbf{2}) \mathrm{Cl}_{2}\right](\mathbf{2})\left[\mathrm{Pd}(\mathbf{L} \mathbf{3}) \mathrm{Cl}_{2}\right](\mathbf{3}),\left[\mathrm{Pd}(\mathbf{L} \mathbf{4}) \mathrm{Cl}_{2}\right](\mathbf{4})$, $[\mathrm{Pd}(\mathbf{L} 2) \mathrm{ClMe}](\mathbf{5})$ and $\left[\mathrm{Pd}(\mathbf{L 2}) \mathrm{ClPPh}_{3}\right] \mathrm{BAr}_{4}(\mathbf{6})$, were prepared following our recently published procedure. $^{14}$ 


\subsection{Density Functional Theory (DFT) studies}

DFT calculations were performed in a gas phase to identify the energy-minimized structures based on B3LYP/LANL2DZ (Los Almos National Laboratory 2 double $\zeta$ ) level theory. ${ }^{16}$ A split bases set, LANL2DZ for palladium and $6-113 \mathrm{G}$ for all other atoms was used to optimize the geometries and energies of the complexes. The Gaussian09 suite of programs was used for all the computations.

\subsection{General procedure for the hydrogenation reactions of alkenes and alkynes}

The catalytic hydrogenation reactions were performed in a stainless steel autoclave equipped with temperature control unit and a sample valve. In a typical experiment, styrene $(0.5$ $\mathrm{mL}, 4.20 \mathrm{mmol})$ and complex $2(3.47 \mathrm{mg}, 0.007 \mathrm{mmol}, \mathrm{S} / \mathrm{C} 600)$ were dissolved in toluene (50 $\mathrm{mL})$. The reactor was evacuated, flushed with nitrogen and the catalytic solution was introduced to the reactor via a cannula. The reactor was purged three times with hydrogen, and then set at the equipped pressure, heated to the desired temperature and the reaction stirred at $500 \mathrm{rpm}$. At the end of the reaction time, the reactor was cooled, excess hydrogen vented off. Samples for GC analyses were drawn via a syringe, filtered using $0.45 \mu \mathrm{m}$ micro filters and analyzed by Varian CP-3800 GC (ZB-5HT column $30 \mathrm{~m} \times 0.25 \mathrm{~mm} \times 0.10 \mu \mathrm{m}) \mathrm{GC}$ instrument to determine the percentage conversion of styrene to ethylbenzene. Standard ethylbenzene (97\%), trans-2-hexene (97\%), cis-2-hexene (98\%), trans-2-octene (98\%) and octane (98\%) were purchased from SigmaAldrich and used to confirm the presence and composition of hydrogenation products. 


\section{Results and discussion}

\subsection{Hydrogenation reactions of alkenes and alkynes using palladium (II) complexes 1-6}

\section{as catalysts}

Preliminary evaluations of complexes 1-6 (Chat 1) in the hydrogenation of styrene were performed at 5 bar of $\mathrm{H}_{2}$ pressure, $30{ }^{\circ} \mathrm{C}$ and [styrene]:[Cat] $=600: 1$. Under these conditions, all the complexes showed catalytic activities to afford $100 \%$ ethylbenzene with conversions ranging from $54 \%$ to $99 \%$ within $1.5 \mathrm{~h}$ (Fig. S1). In order to fully account for the role of complexes 1-6 in the observed catalytic hydrogenation reactions, control experiments were conducted without the use of the palladium(II) complexes under similar reaction conditions. The low percentage conversions of $4 \%$ within $10 \mathrm{~h}$ (Table 1 , entry 7) confirmed that complexes 1-6 were responsible for the observed higher catalytic activities. We thus further carried out detailed kinetics, selectivity and theoretical studies to establish the structure-activity relationship.
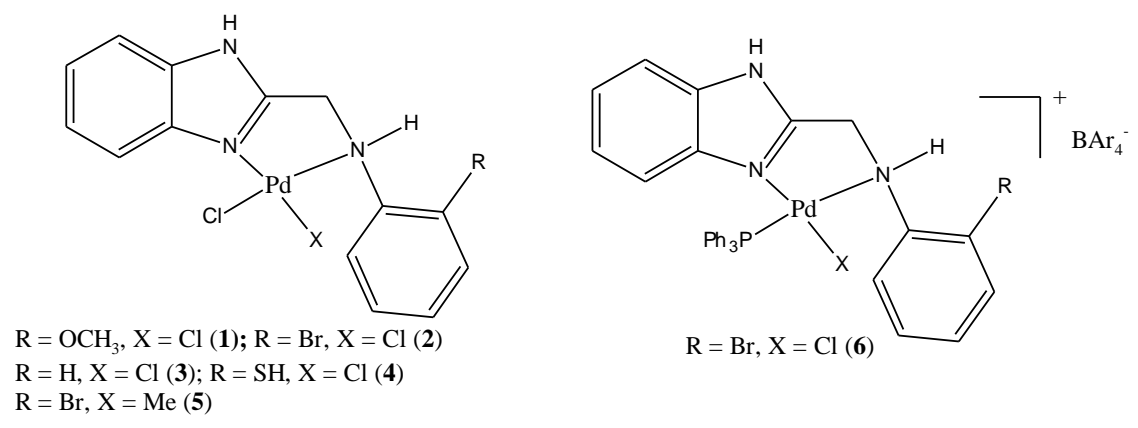

Chart 1: Neutral and cationic (benzoimidazol-2-ylmethyl)amine palladium (II) complexes 1-6 ${ }^{17}$ used as catalysts in the hydrogenation reactions. 
Table 1: Effect of catalyst structure on the hydrogenation of styrene by complexes 1-6 ${ }^{\mathbf{a}}$

\begin{tabular}{llccc}
\hline Entry & Catalyst & Conversion ${ }^{\mathrm{b}}(\mathrm{mol} \%)$ & $k_{\text {obs }}\left(\mathrm{h}^{-1}\right)$ & $\mathrm{TOF}^{\mathrm{c}}\left(\mathrm{h}^{-1}\right)$ \\
\hline 1 & $\mathbf{1}$ & 74 & $0.91( \pm 0.03)$ & 296 \\
2 & $\mathbf{2}$ & 92 & $1.67( \pm 0.01)$ & 368 \\
3 & $\mathbf{3}$ & 78 & $0.98( \pm 0.05)$ & 312 \\
4 & $\mathbf{4}$ & 86 & $1.38( \pm 0.07)$ & 344 \\
5 & $\mathbf{5}$ & 54 & $0.56( \pm 0.04)$ & 215 \\
6 & $\mathbf{6}$ & 99 & $2.93( \pm 0.1)$ & 396 \\
$7^{\mathrm{d}}$ & - & 4 & - & - \\
\hline
\end{tabular}

${ }^{a}$ Conditions: styrene, [substrate]/catalyst;600:1; substrate, $4.20 \mathrm{mmol}$; catalyst; $0.007 \mathrm{mmol}$; solvent, toluene $(50 \mathrm{~mL})$; pressure, 5 bar; temperature, $30^{\circ} \mathrm{C}$; time, $1.5 \mathrm{~h}$. ${ }^{b}$ Determined by GC. ${ }^{\mathrm{c}} \mathrm{TOF}$ in $\mathrm{mol}_{\text {substratemol }} \mathrm{catalyst}^{-1} \mathrm{~h}^{-1} .{ }^{\mathrm{d}}$ Control experiment, no catalyst used, time $10 \mathrm{~h}$.

\subsection{Kinetics of styrene hydrogenation reactions}

\subsubsection{Effect of complex structure on catalytic hydrogenation of styrene by 1-6}

Kinetics of the hydrogenation reactions of styrene were investigated for complexes 1-6 by monitoring the reactions using a GC chromatography. Table 1 contains the initial rate constants derived from the plots of $\operatorname{In}[\text { Sty }]_{0} /[\text { Sty }]_{t} v s$ time (Fig. S2). A linear relationship was established consistent with a pseudo-first order kinetics with respect to styrene for all the complexes. The dependence of the rate of the hydrogenation reactions on styrene substrate can therefore be represented as given in equation 1 .

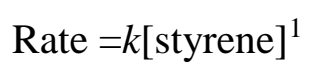

From the rate constants observed, the cationic complex $\mathbf{6}$ was the most active compared (Table 1, entries 2 and 6). This higher catalytic activity could be attributed to the improved solubility of complex 6 (due to the bulky Ar groups) compared to complexes 1-5. ${ }^{11}$ Another 
plausible explanation could be a higher positive charge on the palladium(II) metal atom in the cationic complex 6 relative to the neutral analogues, thus better substrate coordination. ${ }^{8} \mathrm{~A}$ similar trend in the hydrogenation of 1-hexene was reported where higher catalytic activity (TOF $=4000$ $\left.\mathrm{h}^{-1}\right)$ for the cationic complex $\left(\left[\mathrm{Rh}\left(\mathrm{PPh}_{3}\right)_{2} \mathrm{COD}\right]^{+}\right)$compared to TOF $=700 \mathrm{~h}^{-1}$ for the neutral complex $\left[\mathrm{Rh}\left(\mathrm{PPh}_{3}\right)_{3} \mathrm{Cl}\right]$ was observed. ${ }^{18,19} \mathrm{We}$ also observed that the ligand motif had an influence on the catalytic activity. For instance, complex 2, bearing electron withdrawing $\mathrm{Br}$ group on the phenyl ring showed higher catalytic activity, $\left(k_{o b s}\right.$ of $\left.1.67 \mathrm{~h}^{-1}\right)$ than the analogues complex $\mathbf{1}\left(k_{o b s}\right.$ of $0.91 \mathrm{~h}^{-1}$ ), containing the electron donating $\mathrm{OCH}_{3}$ substituent (Table 1, entries and 2). This can also be rationalized from electrophilic metal ${ }^{8}$ center in $\mathbf{2}$ compared to $\mathbf{1}$, consistent with the argument fronted for the cationic complex 6. Another factor that appeared to control the catalytic activity was the $\mathrm{Pd}-\mathrm{Cl} / \mathrm{Me}$ bonds on the complex structure. For example, rate constants of $1.67 \mathrm{~h}^{-}$ ${ }^{1}$ and $0.56 \mathrm{~h}^{-1}$ were observed for complexes 2 and 5 bearing $\mathrm{Pd}-\mathrm{Cl}$ and $\mathrm{Pd}-\mathrm{Me}$ groups respectively (Table 1, entries 2 and 5). This can be assigned to the ease of formation of a Pd-H species, usually presumed to be the active species, from the $\mathrm{Pd}-\mathrm{Cl}$ system compared to the $\mathrm{Pd}-\mathrm{Me}$ analogues. ${ }^{20}$

\subsubsection{Effect of catalyst concentration and hydrogen pressure on the kinetics of hydrogenation reactions of styrene}

Kinetic experiments were further conducted to establish the effects of catalysts concentrations on the hydrogenation reactions of styrene using complex 2 . This was done by varying [styrene]/[2] from 200 to 1000 at constant initial concentration of styrene (Table 2, entries 1-5). A plot of $\operatorname{In}[\text { styrene }]_{0} /[\text { styrene }]_{t} v s$ time (Fig. S3) gave a linear relationship from which the observed rate constants $\left(k_{o b s}\right)$ were derived (Table 2$)$. It was observed that an increase in catalyst concentration resulted in an increase in catalytic activity. For instance $k_{o b s}$ of $2.66 \mathrm{~h}^{-1}$ and $0.91 \mathrm{~h}^{-1}$ 
were obtained at [styrene]/[2] ratios of 600 and 1000 respectively. However, a closer examination of the TOF values at different catalyst loadings paint a different picture. For example, increased [styrene]/[2] ratio (decrease in catalyst concentration) from 600 to 1000 was marked by an increase in TOF from $368 \mathrm{~h}^{-1}$ and $466 \mathrm{~h}^{-1}$ respectively. It is therefore evident that increasing catalyst concentration did not increase the catalytic activity by a similar magnitude and thus higher [substrate]/[catalyst] ratios (lower catalyst loadings) is not only recommended but would also be industrially beneficial with these systems.

The order of reaction with respect to catalyst 2 was extracted from the plot of $-\operatorname{In}\left(k_{o b s}\right) v s$ $-\operatorname{In}[2]$ (Figure 1) and obtained as $0.8 \pm 0.08$. From our previous work, we reported fractional orders on catalyst concentration in hydrogenation reactions of styrene catalyzed by palladium(II) complexes. $^{21,22}$ This fractional order has been associated with possible catalyst aggregation during hydrogenation reactions and/or formation of palladium(0) nanoparticles as the active species. ${ }^{23,24}$ To shed some light on this, mercury poisoning test was conducted by adding few drops of mercury to the reaction solution. ${ }^{23}$ Appreciable drop in catalytic activity from $92 \%$ to $67 \%$ was observed (Table 2, entries 3 and 9), consistent with the generation of active palladium(0) nanoparticles in the catalytic mixture. ${ }^{22}$ However, from the absence of induction periods (Figs. S1-S6) point to a largely homogeneous catalyst system. 


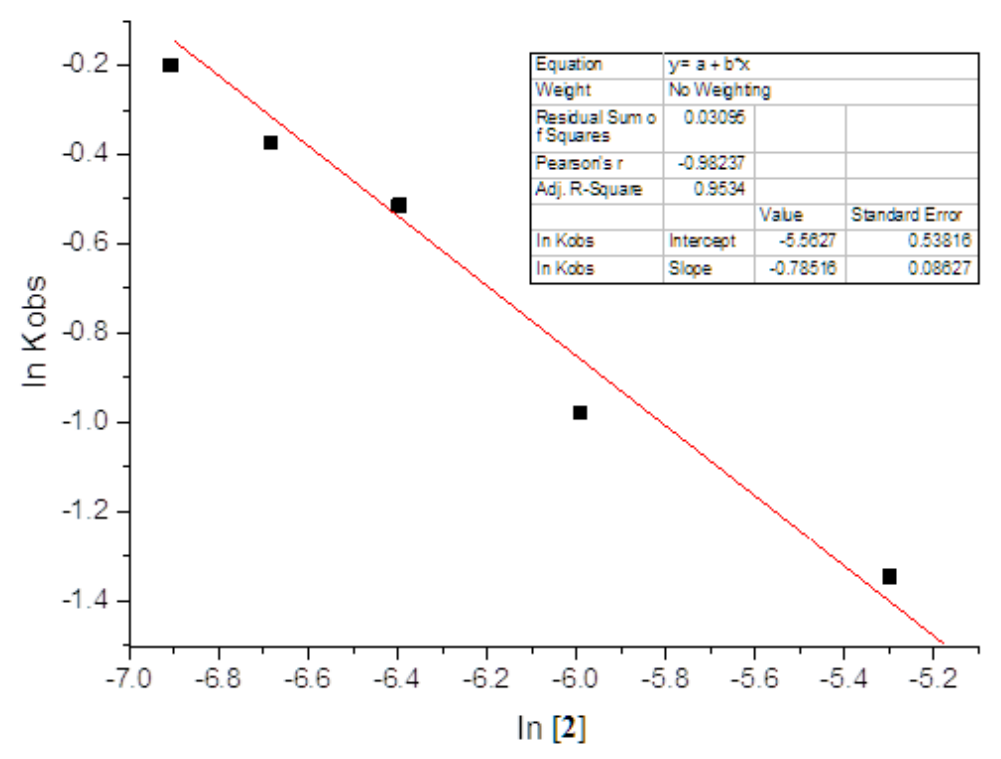

Figure 1: Plot of $\operatorname{In}\left(k_{o b s}\right)$ vs $\operatorname{In}[2]$ for the determination of the order of reaction wit respect to catalyst 2.

The effect of $\mathrm{H}_{2}$ concentration on the kinetics of styrene hydrogenation reactions was also investigated at different $\mathrm{H}_{2}$ pressures of 5 bar to 12.5 bar (Table 2, entries 3, 6-8). From the data obtained, it was evident that an increase in $\mathrm{H}_{2}$ pressure resulted in an increase in the observed rate constants $\left(k_{o b s}\right)$. For example, $k_{o b s}$ of $1.67 \mathrm{~h}^{-1}$ and $2.02 \mathrm{~h}^{-1}$ were recorded at $\mathrm{H}_{2}$ pressures of 5 and 10 bar (Table 2, entries 3 and 6). Linear relationships were observed from the plot of In[Sty $]_{0} /[\text { Sty }]_{\mathrm{t}}$ vs time at different $\mathrm{H}_{2}$ pressures (Fig S4) to generate a rate order of $0.7 \pm 0.1$ with respect to $\mathrm{H}_{2}$ concentration (Figure 2). This fractional and lower order indicates a complex reaction mechanism with respect to $\left[\mathrm{H}_{2}\right]$ and possibly the formation of a $\mathrm{Pd}$-monohydride species as the active species, ${ }^{25}$ and possible catalyst aggregation vide supra. The rate law for the hydrogenation reactions of styrene using catalyst 2 can therefore be expressed as given in equation 2 .

$$
\text { Rate }=k[\text { styrene }]^{1}[\mathbf{2}]^{0.8}\left[P_{H 2}\right]^{0.7}
$$


Table 2: Effect of catalyst concentration and pressure on the hydrogenation of styrene using catalyst $\mathbf{2}^{\mathrm{a}}$

\begin{tabular}{|c|c|c|c|c|c|c|}
\hline Entry & Sub/Cat & $P_{H 2}$ (bar) & $\mathbf{T}\left({ }^{\circ} \mathrm{C}\right)$ & $\operatorname{Conv}(\%)^{b}$ & $k_{o b s}\left(\mathrm{~h}^{-1}\right)$ & TOF $^{c}\left(h^{-1}\right)$ \\
\hline $1^{\mathrm{d}}$ & 200 & 5 & 30 & 99 & $3.84( \pm 0.02)$ & 158 \\
\hline 2 & 400 & 5 & 30 & $>99$ & $2.66( \pm 0.02)$ & 267 \\
\hline 3 & 600 & 5 & 30 & 92 & $1.67( \pm 0.01)$ & 368 \\
\hline 4 & 800 & 5 & 30 & 84 & $1.45( \pm 0.03)$ & 448 \\
\hline 5 & 1000 & 5 & 30 & 70 & $0.91( \pm 0.05)$ & 466 \\
\hline 6 & 600 & 7.5 & 30 & 98 & $2.02( \pm 0.02)$ & 392 \\
\hline $7^{d}$ & 600 & 10 & 30 & 99 & $5.45( \pm 0.13)$ & 475 \\
\hline $8^{e}$ & 600 & 12.5 & 30 & 99 & $6.84( \pm 0.06)$ & 594 \\
\hline $9^{f}$ & 600 & 5 & 30 & 67 & - & 268 \\
\hline
\end{tabular}

${ }^{\mathrm{a}}$ Conditions: styrene, $4.36 \mathrm{mmol}$; solvent; toluene $(50 \mathrm{~mL})$; time, $1.5 \mathrm{~h}$. ${ }^{\mathrm{b}}$ Determined by GC. ${ }^{\mathrm{c} T O F}$ in mol $_{\text {substratemol }}$ catalyst $^{-1} \mathrm{~h}^{-1}$. ${ }^{\mathrm{d}}$ Time, $1.25 \mathrm{~h}$, ${ }^{\mathrm{e}}$ Time, $1.0 \mathrm{~h} .{ }^{\mathrm{f}}$ Mercury drop test $(5$ drops of mercury were added to the reaction mixture). 


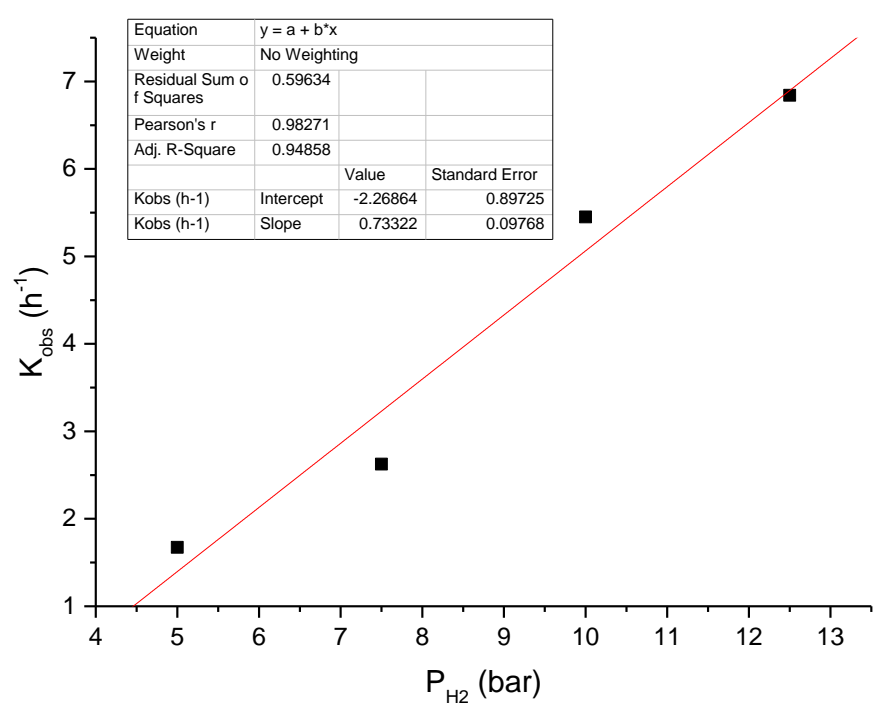

Figure 2: Plot of $k_{o b s} v s \mathrm{P}_{\mathrm{H} 2}$ (bar) for the determination of the order of reaction with respect to $\mathrm{H}_{2}$ pressure.

\subsubsection{Effect of temperature and solvents on styrene hydrogenation kinetics}

The effect of temperature on the kinetics of hydrogenation of styrene using catalyst 2 was investigated by comparing the catalytic activities of 2 from $30{ }^{\circ} \mathrm{C}$ to $60{ }^{\circ} \mathrm{C}$ (Table 3 , entries $1-4$ ). The observed rate constants at different temperatures in Table 3 were extracted from the plot of In[styrene $]_{0} /[\text { styrene }]_{t} v s$ time (Fig. S5). Expectedly, a significant increase in the rate constant from $1.67 \mathrm{~h}^{-1}$ to $6.30 \mathrm{~h}^{-1}$ was recorded with an increase in reaction temperature from $30{ }^{\circ} \mathrm{C}$ to $60{ }^{\circ} \mathrm{C}$. The overall activation energy ( $E a$ ) of the hydrogenation of styrene using $\mathbf{2}$ was calculated from the Arrhenius plot of In $k_{o b s} v s$ 1/T (Figure 3a) as $35.61 \pm 1.6 \mathrm{~kJ} \mathrm{~mol}^{-1}$. This value is comparable to the

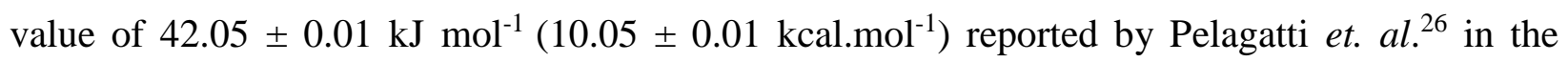
hydrogenation reaction of alkenes at $40^{\circ} \mathrm{C}$. These results in good agreement with the similar TOFs of $600 \mathrm{~h}^{-1}$ and $580 \mathrm{~h}^{-1}$ obtained for 2 the Pelagatti catalysts respectively. The Eyring plot in Figure $3 \mathrm{~b}$ was used to obtain the enthalpy of activation $\left(\Delta H^{+}=32.98 \pm 1.9 \mathrm{~kJ} \mathrm{~mol}^{-1}\right)$ and entropy of 
activation $\left(\Delta \mathrm{S}^{\neq}=-1112.74 \pm 1.9 \mathrm{~J} \mathrm{~mol}^{-1} \mathrm{~K}^{-1}\right)$. The significance of these thermodynamic parameters is that they support homogeneous nature of catalyst as has been previously reported by others. ${ }^{26,27}$ Typical heterogeneous catalysts in which the hydrogenation reactions are diffusion controlled display lower $E_{\mathrm{a}}$ between $8 \mathrm{~kJ} \mathrm{~mol}^{-1}$ to $17 \mathrm{~kJ} \mathrm{~mol}^{-1}$ well below the values for $E_{a}$ and $\Delta H^{\ddagger}$ of $35.61 \pm 1.6 \mathrm{~kJ}$ $\mathrm{mol}^{-1}$ and $32.98 \pm 1.9 \mathrm{~kJ} \mathrm{~mol}^{-1}$ obtained for catalyst 2 respectively. ${ }^{26}$

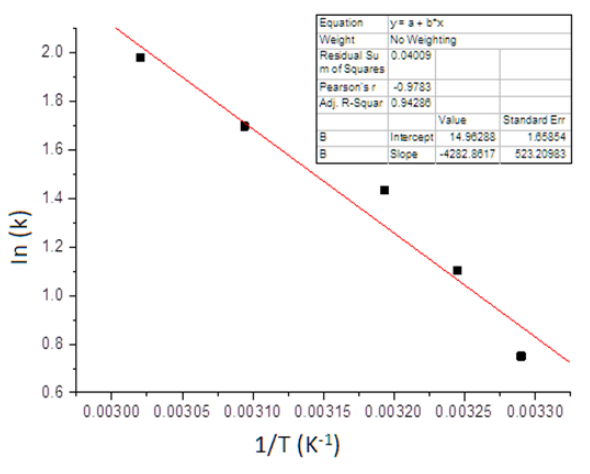

(a)

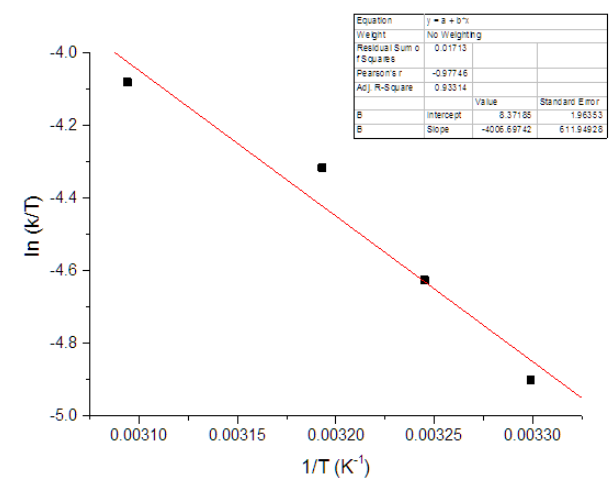

(b)

Figure 3: Arrhenius plot (a) and Eyring plot (b) for the determination of the $E_{a}=35.61 \pm 1.6 \mathrm{~kJ}$ $\mathrm{mol}^{-1} \Delta H^{\ddagger}=32.98 \pm 1.9 \mathrm{~kJ} \mathrm{~mol}^{-1}$, and $\Delta S^{\ddagger}=-1112.74 \pm 1.9 \mathrm{~J} \mathrm{~mol}^{-1} \mathrm{~K}^{-1}$

We also studied the effects of solvents using toluene, THF, dichloromethane, methanol and DMSO in the hydrogenation reactions of styrene using complex 2 (Table 3, entries 1, 5 - 7). The order of reactivity was established as follows: $\mathrm{DMSO}<$ methanol $<\mathrm{THF}<$ toluene. For example, higher catalytic activities were obtained in toluene $\left(k_{o b s}\right.$ of $1.67 \mathrm{~h}^{-1}$, TOF $\left.=368 \mathrm{~h}^{-1}\right)$ than methanol $\left(k_{o b s}\right.$ of 0.52 $\mathrm{h}^{-1}$, TOF $\left.=183 \mathrm{~h}^{-1}\right)$. This trend is in line with different coordinating abilities of the solvents; where strongly coordination solvents are known to compete with the alkene substrate, for the active site resulting in diminished activities. ${ }^{28,29}$ Consistent with our observations, Unver and Yilmaz recently 
reported $27 \%$ and $63 \%$ conversions in DMSO and toluene solvents respectively in the hydrogenation of 1-octene catalyzed by ruthenium complexes. ${ }^{30}$

Table 3: Effect of temperature and solvent the hydrogenation of styrene using catalyst $\mathbf{2}^{\mathbf{a}}$

\begin{tabular}{clcccc}
\hline Entry & Solvent & T $\left({ }^{\mathbf{0}} \mathbf{C}\right)$ & Conv $(\boldsymbol{\%})^{\mathbf{b}}$ & $\boldsymbol{k}_{\text {obs }}\left(\mathbf{h}^{-\mathbf{1}}\right)$ & TOF $\left(\mathbf{h}^{-\mathbf{1}}\right)^{\mathbf{c}}$ \\
\hline 1 & Toluene & 30 & 92 & $1.67( \pm 0.01)$ & 368 \\
$2^{\mathrm{d}}$ & Toluene & 40 & 99 & $4.19( \pm 0.03)$ & 475 \\
$3^{\mathrm{d}}$ & Toluene & 50 & $>99$ & $5.46( \pm 0.1)$ & 480 \\
$4^{\mathrm{e}}$ & Toluene & 60 & $>99$ & $6.30( \pm 0.07)$ & 600 \\
5 & Methanol & 30 & 49 & $0.61( \pm 0.08)$ & 196 \\
6 & DCM & 30 & 68 & $0.90( \pm 0.04)$ & 272 \\
7 & THF & 30 & 86 & $1.40( \pm 0.03)$ & 343 \\
8 & DMSO & 30 & 35 & $0.52( \pm 0.06)$ & 183 \\
\hline
\end{tabular}

aConditions: styrene, $4.36 \mathrm{mmol}$; solvent; toluene $(50 \mathrm{~mL})$; [styrene]/[2] $=600$; time, $1.5 \mathrm{~h}$,

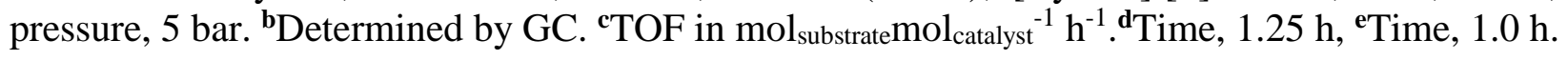

\section{Effect of alkene and alkyne substrates on styrene hydrogenation kinetics and} selectivity

Complex 2 was further used to investigate the hydrogenation reactions of a range of alkene and alkyne substrates: 1-hexene, 1-octene, 1-nonene, 1-decene, phenyl-acetylene, 1-hexyne and 1-octyne. The initial rate constants $\left(k_{o b s}\right)$ of each substrate were determined from the plot of $\operatorname{In}[\mathrm{Sty}]_{0} /[\mathrm{Sty}]_{\mathrm{t}} v s$ time (Fig. S6). The results obtained generally showed that alkynes were more reactive compared to the corresponding alkenes. ${ }^{31,32}$ For example, $k_{o b s}$ of $0.69 \mathrm{~h}^{-1}$ and $k_{o b s}$ of $2.92 \mathrm{~h}^{-1}$ were obtained for 1-hexene and 1-hexyne (Table 4, entries 2 and 7). The alkyl chain length had a profound effect on the reactivity of the substrates, in which shorter chains were more reactive. For instance, $k_{o b s}$ of $0.69 \mathrm{~h}^{-1}$ and $0.50 \mathrm{~h}^{-1}$ were observed for 1-hexene and 1-decene respectively (Table 3, entries 2 and 5). The decrease in catalytic activity with alkene chain has been attributed to poor coordinating abilities of higher alkenes 
to the active metal center. ${ }^{11}$ With respect to alkenes, the best catalytic activity was obtained using styrene $\left(k_{o b s}=1.67 \mathrm{~h}^{-1}\right)$; a feature that has largely been assumed to arise from the delocalized double bonds in the phenyl ring. ${ }^{33}$ The product distribution of terminal alkenes and alkynes was similar to our recent reports; ${ }^{21,22}$ hydrogenation reactions of terminal alkenes were followed by isomerization reactions to give the corresponding internal alkenes, while alkyne hydrogenation reactions occurred in two steps to produce the respective alkenes and alkanes (Figure 4).

Table 4: Effect of substrate on the catalytic activity of complex $2^{\mathbf{a}}$

\begin{tabular}{|c|c|c|c|c|}
\hline Entry & Substrate & $k_{o b s}\left(\mathrm{~h}^{-1}\right)$ & $\operatorname{TOF}\left(h^{-1}\right)^{b}$ & \%Alkane \\
\hline 1 & Styrene & $1.67( \pm 0.01)$ & 368 & 92 \\
\hline 2 & 1-Hexene & $0.69( \pm 0.06)$ & 284 & 71 \\
\hline 3 & 1-Octene & $0.58( \pm 0.13)$ & 268 & 67 \\
\hline 4 & 1-Nonene & $0.56( \pm 0.05)$ & 236 & 59 \\
\hline 5 & 1-Decene & $0.50( \pm 0.07)$ & 220 & 55 \\
\hline 6 & Phenyl-acetylene & $2.40( \pm 0.05)$ & 400 & 100 \\
\hline 7 & 1-Hexyne & $2.92( \pm 0.04)$ & 260 & 65 \\
\hline 8 & 1-Octyne & $2.29( \pm 0.02)$ & 208 & 52 \\
\hline
\end{tabular}

${ }^{a}$ Conditions: substrate, substrate/catalyst $=600$; solvent, toluene; pressure, 5 bar; temperature, 30 ${ }^{\circ} \mathrm{C}$; time, $1.5 \mathrm{~h}$. ${ }^{\text {b }} \mathrm{TOF}$ in mol $_{\text {substratemol }}$ catalyst $^{-1} \mathrm{~h}^{-1}$. 'Selectivity towards alkane hydrogenation products after $1.5 \mathrm{~h}$. 


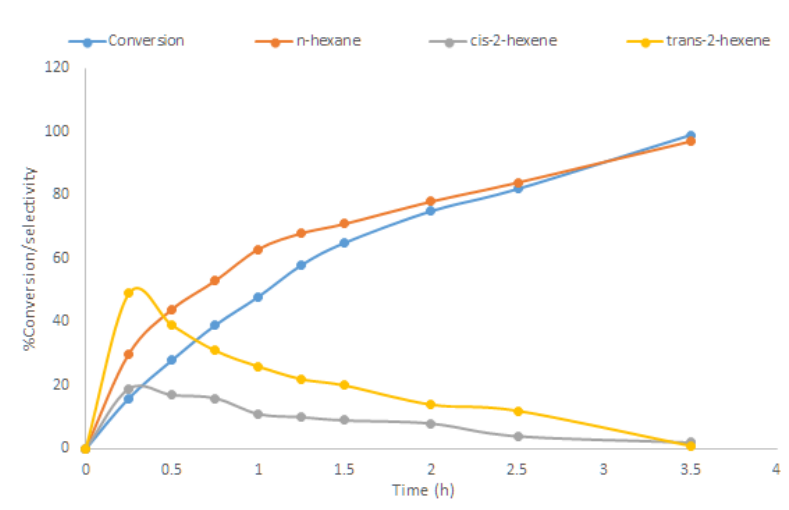

(a)

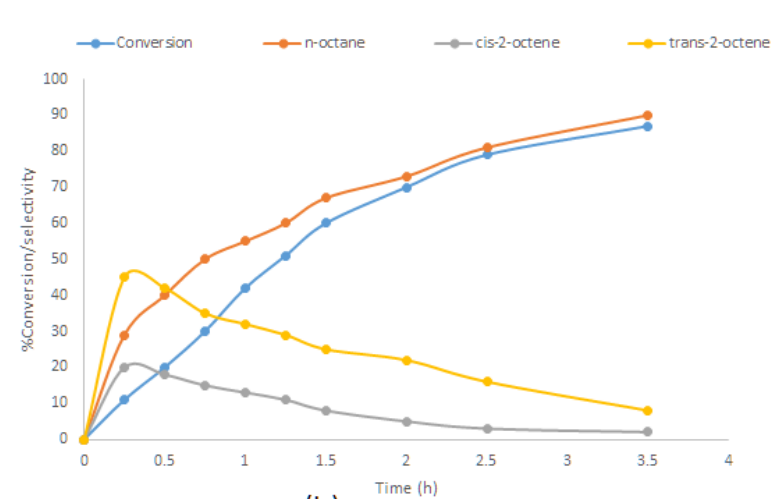

(b)

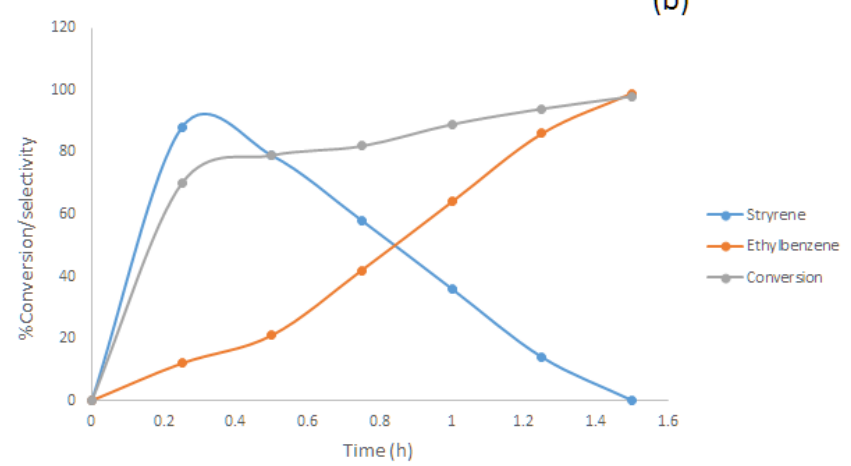

(a)

Figure 4. Product distribution over time in the hydrogenation of (a) 1-hexene, (b) 1-octene and (c) phenyl-acetylene using complex $\mathbf{2}$ as a catalyst.

\subsection{Theoretical insights of the hydrogenation reactions of alkenes}

Density Functional Theory (DFT) calculations were conducted in order to have an understanding of the effect of the ligand motif and catalyst structure on the catalytic activities of complexes 1-4. The geometries-optimized structures and frontier orbital energy (HOMO and LUMO) maps are summarized in Table 4 and Fig. S7, respectively. The relationship between HOMO-LUMO energy gaps and the catalytic activity was established to show a significant correlation. For example, while complex 1 with HOMO-LUMO energy gap of $121.28 \mathrm{kcal} \mathrm{mol}^{-1}$ displayed $k_{o b s}$ of $0.91 \mathrm{~h}^{-1}$, complex 2, with HOMO-LUMO energy gap of $104.48 \mathrm{kcal} \mathrm{mol}^{-1}$ had $k_{o b s}$ of $1.67 \mathrm{~h}^{-1}$ (Table 4). HOMO-LUMO energy gaps promote coordination of the substrate to the 
metal center ${ }^{34}$, which is in good agreement with the observed catalytic trends. The charge on the metal ion was also observed to influence the catalytic activities of complexes 1-4 (Fig. S8). For instance, catalyst $\mathbf{2}$ carrying a positive charge of 0.392 was more active than catalyst $\mathbf{1}$, with a charge of 0.326 on the palladium (II) atom. This trend is in agreement with a more facile substrate coordination to an electrophilic palladium atom. ${ }^{34}$

Table 4 DFT calculated data for palladium (II) complexes

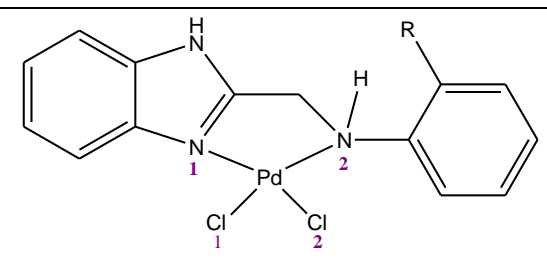

$\mathrm{R}=\mathrm{OCH}_{3}(\mathbf{1}) ; \mathrm{Br}(\mathbf{2}) ; \mathrm{H}(\mathbf{3}) ; \mathrm{SH}(\mathbf{4})$

\begin{tabular}{lllll}
\hline Parameter & $\mathbf{1}$ & $\mathbf{2}$ & $\mathbf{3}$ & $\mathbf{4}$ \\
\hline LUMO $(\mathrm{eV})$ & -1.87 & -1.83 & -1.77 & -1.81 \\
HOMO $(\mathrm{eV})$ & -7.13 & -6.38 & -6.75 & -6.35 \\
$\Delta \mathrm{E}_{\mathrm{L}-\mathrm{H}}$ & 5.26 & 4.55 & 4.98 & 4.54 \\
$\Delta \varepsilon\left[\mathrm{kcal} \mathrm{mol}^{-1}\right]$ & 121.28 & 104.48 & 114.92 & 104.69 \\
NBO charges $(\mathrm{Pd})$ & 0.326 & 0.392 & 0.354 & 0.358 \\
TOF $\left(\mathrm{h}^{-1}\right)^{\mathrm{a}}$ & 296 & 368 & 312 & 344 \\
$k_{\mathrm{obs}}\left(\mathrm{h}^{-1}\right)$ & 0.91 & 1.67 & 0.98 & 1.38 \\
\hline
\end{tabular}

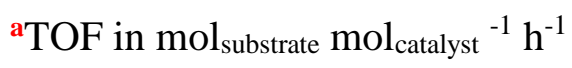




\subsection{Proposed mechanism of the hydrogenation of styrene}

The dependency of the rate of hydrogenation reactions on styrene, catalyst and hydrogen pressure (eq. 2) is consistent with either of the following equations 3 and 4 . The partial and lower order of reaction with respect to $\left[\mathrm{H}_{2}\right]$ of $0.7 \pm 0.1$ support the formation of a monohydride species as the rate determining step. This points to the first mechanism (3) as the most probable pathway. ${ }^{35}$
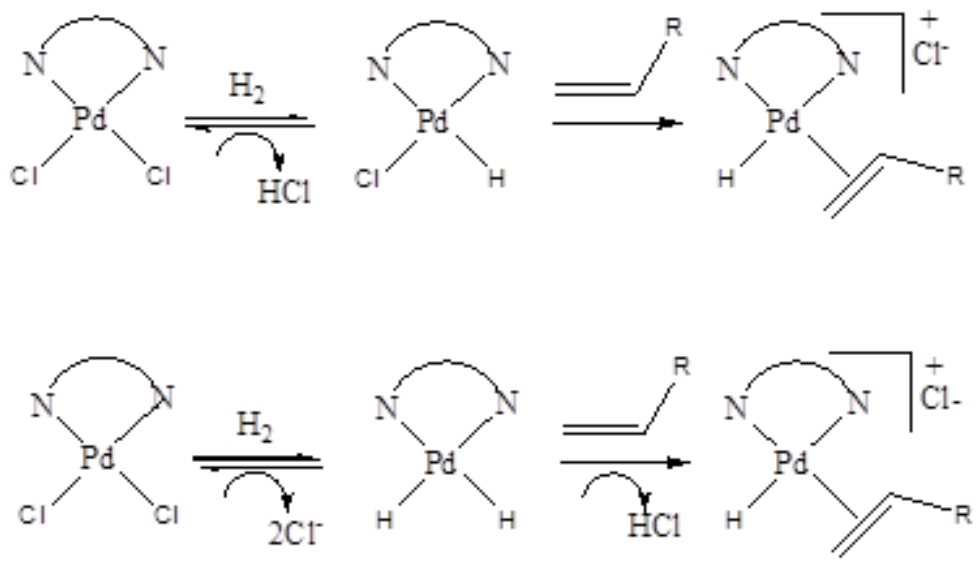

(4)

Based on the kinetics data and the dependency of the rates of hydrogenation reactions on the coordinating ability of the solvent used, we can now propose two mechanisms as shown in Scheme 1. The first pathways is a classical route usually observed for bidentate systems where dihydride species is not favored, thus formation of the monohydride species $\mathbf{2 a} .^{36}$ In the second pathway (B), the presence of a coordinating solvent leads to the formation of the solvated species $\mathbf{2}$-I, consistent with the earlier proposals by Halper. ${ }^{37}$ Depending on the coordinating ability of the solvent used, substrate addition to give $\mathbf{2 b - I I}$ may be hindered leading to lower catalytic activities, consistent with the observed lower activities in methanol in comparison to toluene. In both, routes, the ratedetermining step is the oxidative addition of hydrogen to give the $\mathrm{Pd}^{\text {(IV) }}$ species $\mathbf{2} \mathbf{d}$ and $\mathbf{2}-\mathbf{I V}$, in line with observed lower partial orders of 0.7 with respect to $\left[\mathrm{H}_{2}\right]$. 


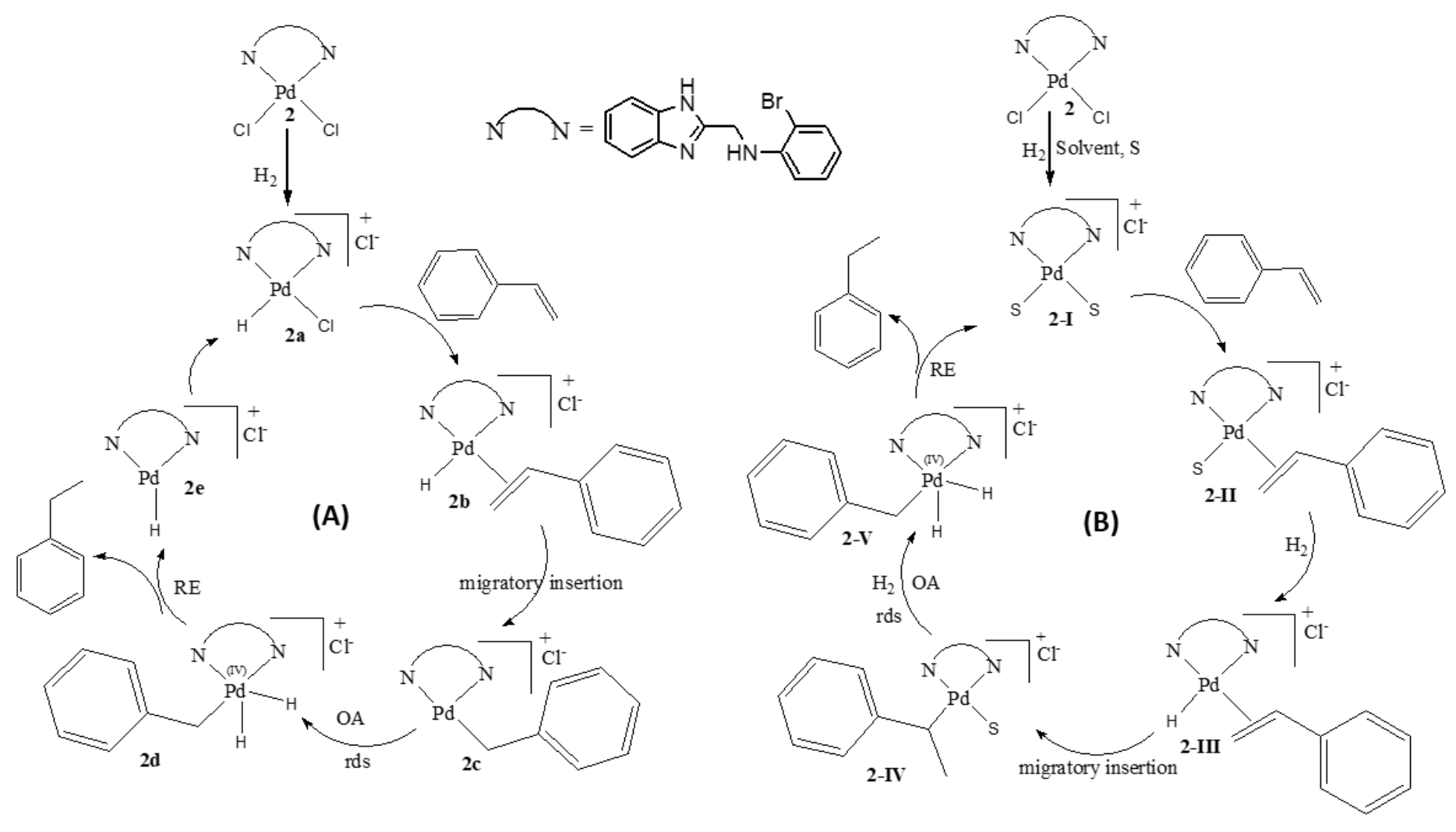

Scheme 1: Proposed mechanistic pathway for the hydrogenation of styrene catalyzed by complex $\mathbf{2}$ in the presence of non-coordinating (A) and coordinating (B) solvents.

\section{Conclusions}

In summary, we have established that neutral and cationic palladium (II) complexes anchored on (benzoimidazol-2-ylmethyl)amine ligands form active catalysts for the hydrogenation reactions of alkenes and alkynes in which isomerization of terminal alkenes also occur. The electrophilicity of the metal palladium atom of the complexes atom as supported by DFT calculations, enhanced the reactivity of the respective catalysts. Longer chain alkenes showed diminished reactivity while alkynes were generally more reactive compared to the correspond 
alkenes. Kinetics, thermodynamics and mercury drop experiments point to largely homogeneous systems. A mechanistic pathway in which olefin coordination precedes oxidative hydride addition and stabilization of the active species by a coordinating solvent is proposed.

\section{Conflict of interest statement}

The authors declare no conflict of interests in this manuscript with any other third party, individual or organization.

\section{References}

1 K. A. Vallianatou, D. J. Frank, G. Antonopoulou, S. Georgakopoulos, E. Siapi, M. Zervou and I. D. Kostas, Tetrahedron Lett., 2013, 54, 397-401.

2 H. E. Hoelscher, W. G. Poynter and E. Weger, Chem. Rev., 1954, 54, 575-592.

3 C. Bianchini, A. Meli, M. Peruzzini, P. Frediani, C. Bohanna, M. A. Esteruelas and L. A. Oro, Organometallics, 1992, 11, 138-145.

4 D. Schleyer, H. G. Niessen and J. Bargon, New. J. Chem., 2001, 423-

5 J. Navarro, M. Sagi, E. Sola, F. J. Lahoz, I. T. Dobrinovitch, A. Katho, F. Joo and L. A. Oro, Adv. Synth. Catal., 2003, 345, 280-288.

6 F. Nerozzi, Platin. Met. Rev., 2012, 56, 236-241.

7 M. Irfan, T. N. Glasnov and C. O. Kappe, Chem. Sus. Chem, 2011, 4, 300-316.

8 E. Negishi, Handbook of Organopalladium Chemistry for Organic Synthesis, Wiley \& Sons, New York, 2002, 1, 229-247.

9 A. Bacchi, M. Carcelli, M. Costa, A. Leporati, E. Leporati, P. Pelagatti, C. Pelizzi and G. Pelizzi, J. Organomet. Chem., 1997, 535, 107-120.

10 D. Drago and P. S. Pregosin, Organometallics., 2002, 21, 1208-1215.

11 P. W. N. M. Leeuwen and J. C. Chadwick, Homogeneous catalysts : activity-stabilitydeactivation, Wiley-VCH Verlag, 2011.

12 M. W. van Laren, M. A. Duin, C. Klerk, M. Naglia, D. Rogolino, P. Pelagatti, A. Bacchi, C. Pelizzi and C. J. Elsevier, Organometallics, 2002, 21, 1546-1553.

13 M. W. van Laren and C. J. Elsevier, Angew. Chemie Int. Ed., 1999, 38, 3715-3717. 
14 T. A. Tshabalala, S. O. Ojwach and M. A. Akerman, J. Mol. Catal. A Chem., 2015, 406, 178-184.

15 N. W. Attandoh, S. O. Ojwach and O. Q. Munro, Eur. J. Inorg. Chem., 2014, 2014, 30533064.

16 M. J. T. Frisch, G. W. Trucks, H. B. Schlegel, G. E. Scuseria, M. A. Robb, J. R. Cheeseman, G. Scalmani, V. Barone, B. Mennucci, G. A. Petersson, H. Nakatsuji, M. Caricato, X. Li, H. P. Hratchian, A. F. Izmaylov, J. Bloino, G. Zheng, J. L. Sonnenberg, M. Hada, M. Ehara, K. Toyota, R. Fukuda, J. Hasegawa, M. Ishida, T. Nakajima, Y. Honda, O. Kitao, H. Nakai, T. Vreven, J. A. Montgomery Jr., J. E. Peralta, F. Ogliaro, M. Bearpark, J. J. Heyd, E. Brothers, K. N. Kudin, V. N. Staroverov, R. Kobayashi, J. Normand, K. Raghavachari, A. Rendell, J. C. Burant, S. S. Iyengar, J. Tomasi, M. Cossi, N. Rega, J. M. Millam, M. Klene, J. E. Knox, J. B. Cross, V. Bakken, C. Adamo, J. Jaramillo, R. Gomperts, R. E. Stratmann, O. Yazyev, A. J. Austin, R. Cammi, C. Pomelli, J. W. Ochterski, R. L. Martin, K. Morokuma, V. G. Zakrzewski, G. A. Voth, P. Salvador, J. J. Dannenberg, S. Dapprich, A. D. Daniels, O. Farkas, J. B. Foresman, J. V. Ortiz, J. Cioslowski and D. J. Fox, GAUSSIAN 09 (Revision A.1), Gaussian, Inc., Wallingford, CT, 2009.

17 T. A. Tshabalala, S. O. Ojwach and M. A. Akerman, J. Mol. Catal. A Chem., 2015, 406, 178-184.

18 R. R. Schrock and J. A. Osborn, J. Am. Chem. Soc., 1976, 98, 2134-2143.

19 J. A. Osborn, F. H. Jardine, J. F. Young and G. Wilkinson, J. Chem. Soc. A Inorganic, Phys. Theor., 1966, 0, 1711.

20 L. S. Hegedus, J. Chem. Ed., 2000, 77, 15-48.

21 S. O. Ojwach and A. O. Ogweno, Transit. Met. Chem., 2016, 41, 539-546.

22 S. O. Ojwach, A. O. Ogweno and M. P. Akerman, Catal. Sci. Technol., 2016, 6, 5069-5078.

23 J. A. Widegren and R. G. Finke, J. Mol. Catal. A Chem., 2003, 198, 317-341.

24 V. P. Ananikov and I. P. Beletskaya, Organometallics, 2012, 31, 1595-1604.

25 P. J. Rheinlander, J. Herranz, J. Durst and H. A. Gasteiger, J. Electrochem. Soc., 2014, 161, F1448-F1457.

26 P. Pelagatti, A. Bacchi, M. Carcelli, M. Costa, A. Fochi, P. Ghidini, E. Leporati, M. Masi, C. Pelizzi and G. Pelizzi, J. Organomet. Chem., 1999, 583, 94-105.

27 A. M. Kluwer, T. S. Koblenz, T. T. Jonischkeit, K. Woelk and C. J. Elsevier, J. Am. Chem. 
Soc., 2005, 127, 15470-15480.

28 P. J. Dyson and P. G. Jessop, Catal. Sci. Technol., 2016, 6, 3302-3316.

29 F. Yilmaz, A. Mutlu, H. Ünver, M. Kurta and I. Kani, J. Supercrit. Fluids, 2010, 54, 202209.

30 H. Ünver and F. Y1lmaz, Catalysts, 2016, 6, 147.

31 D. Teschner, J. Borsodi, A. Wootsch, Z. Revay, M. Havecker, A. Knop-Gericke, S. D. Jackson and R. Schlogl, Science (80-. )., 2008, 320, 86-89.

32 H. Yoshida, T. Zama, S. Fujita, J. Panpranot and M. Arai, RSC Adv., 2014, 4, 24922.

33 P. K. Santra and P. Sagar, J. Mol. Catal. A Chem., 2003, 197, 37-50.

34 T. Sperger, I. A. Sanhueza, I. Kalvet and F. Schoenebeck, Chem. Rev., 2015, 115, 95329586.

35 K. C. Dewhirst, W. Keim and C. A. Reilly, Inorg. Chem., 1968, 7, 546-551.

36 J. Halpern, D. P. Riley, A. C. S. Chan and J. J. Pluth, J. Am.Chem. Soc., 1977, 99, 80558057.

37 J. Halpern, Science., 1982, 217, 401-407. 